\title{
Cardiovascular outcomes in heart transplant recipients
}

Veenis et al. ${ }^{1}$ made a compelling case for myocardial perfusion imaging (with single-photon emission computed tomography) correlating strongly with prognosis for heart transplant patients. Early detection and prevention of cardiac allograft vasculopathy (CAV) is essential in optimizing outcomes after heart transplantation. The advantages of SPECT MPI include its lack of invasiveness, lack of risk of contrast nephropathy, and sensitivity for diffuse/microvascular disease.

On reading the article, we wondered how the findings compare with other known associations and risk factors for CAV. We wonder if Veenis and colleagues have data relating to the biochemical markers as discussed by Szyguła-Jurkiewicz et al. ${ }^{2}$-such as fibrinogen and NT-proBNP. Other common variables and demographic information may have been captured. Some of these were identified by Kransdorf et al. ${ }^{3}$ as being associated with cardiac allograft vasculopathy, such as body mass index, creatinine level, etiology of cardiomyopathy, and dyslipidemia (in the recipient) as well as donor variables such as age, Body Mass Index, hypertension, smoking, and mechanism of death. If none of these were available, then the prospect of further research certainly beckons.

Interestingly, Veenis et al. ${ }^{1}$ found age (of the recipient, not the donor) was not associated with 5-year mortality, but dyslipidemia was. Kransdorf et al. ${ }^{3}$ demonstrated opposing results in these domains. What of the others, in addition? Further, were they as surprised as we were that diabetes was not significantly associated with CAV as we would have intuitively expected?

\author{
Joseph C. Lee, MBBS, FRACP, FAANMS (D) ${ }^{a, b}$ \\ Nathan Better, MBBS, FRACP, FAANMS, FCSANZ, \\ FASNC $C^{c, d}$ \\ ${ }^{a}$ Department of Medical Imaging, The Prince Charles Hospital, \\ Chermside, QLD 4032, Australia \\ ${ }^{b}$ Faculty of Medicine, University of Queensland, Herston, Australia \\ ${ }^{c}$ Department of Nuclear Medicine, Royal Melbourne Hospital, Grattan \\ St, Melbourne, VIC 3000, Australia \\ ${ }^{d}$ Department of Medicine, University of Melbourne, Parkville, Aus- \\ tralia \\ e-mail: joseph.lee@health.qld.gov.au
}

Author contributions Conception or design of the work; or the acquisition, analysis, or interpretation of data for the work: JCL $60 \% \mathrm{NB}$ $40 \%$. Drafting the work or revising it critically for important intellectual content: JCL 60\%, NB $40 \%$.

Disclosures The authors have declared that they have no financial conflicts of interest.

\section{References}

1. Veenis JF, Boiten HJ, van den Berge JC, et al. Prediction of longterm ( $>10$ year) cardiovascular outcomes in heart transplant recipients: Value of stress technetium-99m tetrofosmin myocardial perfusion imaging. J Nucl Cardiol 2019;26:845-52.

2. Szyguła-Jurkiewicz B, Zakliczyński M, Szczurek W, Skrzypek M, Gąsior M, Zembala M. Perioperative risk factors of cardiac allograft vasculopathy in the long-term follow-up. Transplant Proc 2016;48:1736-41.

3. Kransdorf EP, Loghmanpour NA, Kanwar MK, Temkit MH, Stehlik J. Prediction model for cardiac allograft vasculopathy: Comparison of three multivariable methods. Clin Transplant 2017. https://doi. org/10.1111/ctr.12925.

doi:10.1007/s12350-019-01836-3

Publisher's Note Springer Nature remains neutral with regard to jurisdictional claims in published maps and institutional affiliations.

J Nucl Cardiol 2020;27:1047.

$1071-3581 / \$ 34.00$

Copyright (c) 2019 American Society of Nuclear Cardiology. 